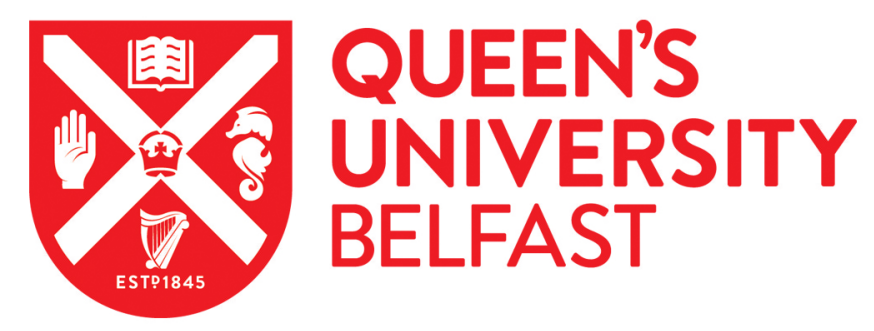

\title{
Liquefaction of Corn Husks and Properties of Biodegradable Biopolyol Blends
}

Briones, R., Rodrigue, J., Martin, P., \& Cunningham, E. (2020). Liquefaction of Corn Husks and Properties of Biodegradable Biopolyol Blends. JOURNAL OF CHEMICAL TECHNOLOGY AND BIOTECHNOLOGY. https://doi.org/10.1002/jctb.6458

Published in:

JOURNAL OF CHEMICAL TECHNOLOGY AND BIOTECHNOLOGY

\section{Document Version:}

Peer reviewed version

Queen's University Belfast - Research Portal:

Link to publication record in Queen's University Belfast Research Portal

Publisher rights

(c) 2020 Society of Chemical Industry. This work is made available online in accordance with the publisher's policies. Please refer to any applicable terms of use of the publisher.

\section{General rights}

Copyright for the publications made accessible via the Queen's University Belfast Research Portal is retained by the author(s) and / or other copyright owners and it is a condition of accessing these publications that users recognise and abide by the legal requirements associated with these rights.

Take down policy

The Research Portal is Queen's institutional repository that provides access to Queen's research output. Every effort has been made to ensure that content in the Research Portal does not infringe any person's rights, or applicable UK laws. If you discover content in the Research Portal that you believe breaches copyright or violates any law, please contact openaccess@qub.ac.uk. 


\title{
LIQUEFACTION OF CORN HUSKS AND PROPERTIES OF \\ BIODEGRADABLE BIOPOLYOL BLENDS
}

Rodrigo Briones ${ }^{\mathrm{a}^{*}}$, Jesús Rodriguez ${ }^{\mathrm{a}}$, Jalel Labidi ${ }^{\mathrm{b}}$, Eoin Cunningham ${ }^{\mathrm{c}}$ and Peter $\operatorname{Martin}^{\mathrm{c}}$

a Centro de Investigación de Polímeros Avanzados, CIPA, Avenida Collao 1202 Edificio Laboratorios CIPA, Concepción, Chile

E-mail: r.briones@cipachile.cl; tel.:+56-41-3111868

${ }^{\mathrm{b}}$ Chemical and Environmental Engineering Department, University of the Basque Country, Plaza Europa 1, 20018, Donostia-San Sebastián, Spain

c Polymer Processing Research Centre (PPRC), Queen’s University of Belfast, United Kingdom.

\begin{abstract}
BACKGROUND: A valorization route of corn husks from agrarian practices was performed by liquefaction using glycerol as liquefaction solvent to obtain biopolyols used as bioadditive in starch blends with the aim to find a useful industrial application in polymer processing.

RESULTS: Low molecular weight liquefied products obtained from a practically total convert reaction can be used for composite formulations (OH number, $310 \mathrm{mg} \mathrm{KOH} / \mathrm{g}$; viscosity, 3.4 Pa.s; and molecular weight $\left.\left(\mathrm{M}_{\mathrm{w}}\right), 549 \mathrm{~g} / \mathrm{mol}\right)$. Concurrently, starch thermoplastic blends using different proportions of biopolyol (40, 30 and 20 wt \%) as plasticizer were produced with maximum torque and plasticization energy ranging from 3.4 to $15.1 \mathrm{Nm}$ and from 1.7 to $9.1 \mathrm{Nm} / \mathrm{min}$. The starch/biopolyol (70/30) sheets obtained
\end{abstract}

This article has been accepted for publication and undergone full peer review but has not been through the copyediting, typesetting, pagination and proofreading process which may lead to differences between this version and the Version of Record. Please cite this article as doi: $10.1002 /$ jctb. 6458 
by thermo-pressing showed similar properties to controls (starch/glycerol: 70/30) such as sensitivity to environment, retrodegradation, biodegradability and density, however, mechanical properties exhibited better performance compared to controls (Young's modulus, $14 \mathrm{MPa}$; strain at break, $33 \%$; and tensile strength, 1.2 MPa), which exhibit a material with major mechanical balance.

CONCLUSION: The adequacy in the conversion of corn husks into biopolyols that could be used as improved bio-based plasticizer to obtain biodegradable blends was revealed in the results. Hence, this study demonstrates that liquefied corn husks residues are sustainable resources with suitable properties for polymer processing, which can be applied in bioplastics and be considered as a value-added feature.

Keywords: lignocellulosic biomass, corn husks, liquefaction, biopolyols, blends

\section{INTRODUCTION}

In the last decade, lignocellulosic wastes emanating from agrarian and industrial practices, currently either dismissed, utilized as animal feed or as a source of energy have been cited as an environmentally friendly, abundant and renewable source of raw materials with suitable characteristics to obtain biopolyols, a potential alternative primary material for polymer and biomaterial synthesis.

A method for obtaining these valued products is via atmospheric liquefaction using polyhydric alcohols. The powerful reaction turned the mixture into a dark liquid with multiple reactive hydroxyl groups. The resulting biopolyol, constituted by components of 
cellulose, hemicelluloses and lignin, is commonly used as a precursor for polymer elaboration, particularly polyurethane materials $[1,2]$. The reaction is carried out using a mixture of glycols as liquefaction solvent. Agricultural lignocellulosic residues have been successfully converted into biopolyols using mainly a polyethylene glycol (PEG) and glycerol mix. Application fields for the polymeric products developed from these residues include a wide range of different materials for areas such as packaging or floating [3-10]. The high volume of glycols from petroleum-derived polyhydric alcohols used is one of the major drawbacks of current biopolyol production from biomass liquefaction due to the considerably increase in production costs. One method to obtain low cost biopolyols is using glycerol as liquefaction solvent. Some published studies have been based on the liquefaction of lignocellulosic biomass such as soybean straw or corn stover by crude glycerol [11-13]. However, there are more raw materials to be considered of interest, commonly deemed as waste, or of little value. The glycerol widespread demand has reached a level in which the price has been considerably devaluated [14].

In a previous work[15], our research group has successfully demonstrated the potential of several liquefied agricultural residues (biopolyols), in order to prepare uniform, opaque and obscure ductile films by casting method with proper thermal and mechanical characteristics. The promising results acquired in this study are related to the utilization of biopolyols for film formulation and its properties promote the research of pioneer low cost bio-based composites for agrarian activities, which could be a promised option to petroleum based materials. On the other side, biopolyols obtained from biomass liquefaction reaction with glycerol as the solvent could be used to assist the processability 
in polymer processing, considering the biopolyol contains oligomers from glycerol, used commonly as plasticizer in thermoplastic material synthesis. In that sense, new thermoplastic composites fields for packaging and agricultural practices can be developed by bio-based biodegradable polymer blends.

In the efforts to reach a better use of agricultural residues, the use of non-toxic and low cost reagents and the decrease of the volume of non-degradable plastic residues, a suitable option comes from the utilization of the biomass liquefaction fluid in order to get interesting biodegradable films and blends.

Corn husks are the thin leaves that cover the corn cobs. This residue, which is rich in cellulose and hemicelluloses, is mostly burned or used for animal feed. The valorization of this biomass and its value-added feature associated, let these new low cost biopolyols be part of structural polymer formulations. Liquefaction reactions imply an advance on the environment protection and an economical improvement. Thus, this is an important aspect for a successful circular bio-economy of the future.

In this context, corn husks originated in agrarian Chilean practices have been considered to investigate. The first part of the present research consists on developing an agroindustrial residue liquefaction with glycerol to get suitable bio-based polyols. Consequently, the study continues determining several physic-chemical features of the resulting products. In addition, the capacity of the liquefied product as bioadditive in starch blends and their characterization was evaluated, and thereby to find a useful industrial application in polymer processing. Biopolyols, blends and sheets samples were examined by several instrumental analysis and conventional methods. 


\section{MATERIAL AND METHODS}

\subsection{Materials}

Corn husks were gathered following the harvest of corn (Zea mays L.) in Bío-Bío region (southern portion of central Chile). Corn husks free of small stones, dust and soil was washed with water, air dried, milled in a commercial mill (Retsch SM 300, Germany) to generate particles and sieved to the particle size of 0.3-0.6 mm (No. 30-50). The resulting powder was oven dried at $60^{\circ} \mathrm{C}$ up to a humidity range about 2-4 \% (determined by dry weight in oven at $103^{\circ} \mathrm{C}$ until constant weight) and preserved at room temperature prior to analysis. The chemical composition of the raw material was determined following standard methods including ash content $(2.5 \% \pm 0.4$, TAPPI T211 om-93), ethanoltoluene extractives $(16.5 \% \pm 0.9$, TAPPI T $204 \mathrm{~cm}-97)$, acid insoluble lignin $(6.5 \% \pm 0.7$, TAPPI T222 om-98)[16]; cellulose $(48.6 \% \pm 0.9)$ and hemicelluloses $(16.1 \% \pm 0.9)$ by Rowell, 1983[17].

Commercial glycerol (G, 99\% purity) and sulfuric acid (SA, $96 \%$ purity) were used as solvent and catalyst in the liquefaction process, respectively to obtain biopolyols. All used chemicals were reagent grade supplied by Merck Company. Soluble (in water $25^{\circ} \mathrm{C}$ ) potato starch (S2004 Sigma) was used as main polymer matrix for starch/biopolyol blends formulation.

\subsection{Liquefaction process}

Glycerol (G) was used as solvent in the liquefaction process. G and SA (3 wt\% of the solvent) were added into a three neck flask reactor (2000 mL) equipped with mechanical stirrer, temperature control and condenser. When the temperature of the liquefying 
chemicals reached the maximal value $\left(130,140,150,160\right.$, and $\left.170{ }^{\circ} \mathrm{C}\right)$, a specific quantity of oven dried corn husk powder was added gradually. The mixture was continuously stirred during the liquefaction process to obtain homogeneous liquefied product. When reaction time was reached, the vessel was quickly immersed in cold water to stop the reaction. After cooling, the liquefied mixture was washed several times with acetone until filtrate was colorless and it was filtered under vacuum. Then the acetone was removed from the liquefied product using a rotary evaporator (at $50{ }^{\circ} \mathrm{C}$ and 0.8 bar). The residue (solid phase) was washed with acetone, dried in oven at $105 \pm 5^{\circ} \mathrm{C}$ for $12 \mathrm{~h}$ until constant weight. After it was conditioned in a desiccator and was weighed to determine the yield of liquefied product.

$$
\eta=\left[1-M / M_{0}\right] \times 100
$$

Where $\eta$ is the yield of liquefied product (\%); $M_{0}$ is the weight of initial dry corn husks (g); and $M$ is the weight of the solid residue of liquefaction.

\subsection{Characterization of liquefied products}

Chemical structure of glycerol and liquefied product obtained was evaluated by attenuated-total reflection infrared (ATR-IR) spectroscopy by direct transmittance in a single-reflection ATR system. Infrared spectra were registered on a PerkinElmer Spectrum Two Fourier Transform Infrared Spectrometer. Each sample was registered over 20 scans in the range from 4000 to $800 \mathrm{~cm}^{-1}$, with a resolution of $2 \mathrm{~cm}^{-1}$.

Physical and chemical characteristics acquired at the maximum level of liquefied products yields were obtained. Hydroxyl number ( $\mathrm{IOH}$ ) was determined by Hassan and Shukry [5] method where each treated sample of liquefied product was valued with $1 \mathrm{M}$ 
sodium hydroxide solution to the equivalence point applying a $\mathrm{pH}$ meter. The $\mathrm{I}_{\mathrm{OH}}$ for the liquefied products were corrected because of their acidity. The acid number $\left(\mathrm{I}_{\mathrm{AC}}\right)$ for the samples was determined under standard methods ASTM 2008 [18] where each sample of liquefied product dissolved in a solvent mixture of dioxane and water was titrated with $0.1 \mathrm{M}$ potassium hydroxide solution in ethanol, to the equivalent point with a $\mathrm{pH}$ meter. Both, $\mathrm{I}_{\mathrm{OH}}$ and $\mathrm{I}_{\mathrm{AC}}$ of the samples were procured by the difference in titration of blank and the sample solution.

The molecular weight of the liquefied products was determined by GPC (SHIMADZU, Prominence Auto Sampler) equipped with UV SPD-20AV and IR RID-10A detectors and Phenogel column. The liquid phase was tetrahydrofuran, which had a flow rate of 1.0 $\mathrm{mL} / \mathrm{min}$. The column temperature was $30{ }^{\circ} \mathrm{C}$. The average molecular weight of the samples was calculated by using a calibration curve of monodisperse polystyrene standards.

Data of viscosity of liquefied products were determined at $25{ }^{\circ} \mathrm{C}$ employing a digital Brookfield Viscometer (Fungilal, Smart L model), by using a spin \#1 spindle at 100 r.p.m. Furthermore, various characteristics including density, moisture content $(\mathrm{H})$ by Karl Fisher method and pH using a calibrated pH-meter (PC510-Oakton) were obtained.

\subsection{Preparation of starch/biopolyol blends and ensuing sheets}

Thermoplastic starch was prepared by addition of liquefied product (20, 30 and $40 \mathrm{wt} \%$ starch-based) followed by pre-mixing using high speed mixer at $3000 \mathrm{rpm}$ for $5 \mathrm{~min}$. The compositions were selected with the aim to obtain blends with physical and mechanical properties adequate for extrusion process and were taking into account values found in 
previously published studies for several starch blends that use glycerol as plasticizer ${ }^{22,23}$. After this preliminary step, the resulting blend was melt-mixed using Brabender internal mixer (Plastograph EC plus, Mixer 50EHT32, Germany) at $120^{\circ} \mathrm{C}$ and rotor speed of 60 r.p.m. for 6 minutes and torque variation as a function of time was recorded. The torque values of maximum peak and steady state, and the plasticization energy were determined from the torque rheometer data, which were subjected to analysis of variance (ANOVA) to determine statistical differences. Samples were identified specifying the wt \% of the liquefied product. For example, in the label 70S30L corresponded to 70 to the wt \% of starch (S), and 30 to the wt \% of liquefied product (L). Table 2 summarizes composition, rheological, physical and tensile properties of evaluated blends. The resulting blends were granulated by means of a blade mill equipped with a nominal $2 \mathrm{~mm}$ mesh and thermopressed in a brass plate mold (180 $\mathrm{mm}$ x $30 \mathrm{~mm}$ x $1 \mathrm{~mm})$ for $15 \mathrm{~min}$ at $130{ }^{\circ} \mathrm{C}$ between non-stick sheets in order to obtain sheets with $1 \mathrm{~mm}$ thickness. For this purpose a Labtech Engineering hydraulic press was operated. A pressure of $16 \mathrm{MPa}$ was applied and maintained, even during the cooling period until $60{ }^{\circ} \mathrm{C}$ was reached to avoid foaming of the sheet from steam bubbles escaping. All samples were pre-conditioned at 58\% RH (23 ${ }^{\circ} \mathrm{C}$ ) for at least 2 days prior to testing.

\subsection{Properties of blends and sheets}

Scanning electron microscopy (SEM) analysis was executed in order to study the surface of the sheets. Samples were analyzed in a scanning electron microscope (JEOL-JSM 6380 LV, Tokyo, Japan). The sheets were covered with a gold film of ca. $50 \mathrm{~nm}$ and the images were taken at an accelerating potential of $20 \mathrm{kV}$. 
For differential scanning calorimetry (DSC) analysis, $5 \mathrm{mg}$ of samples was placed in an aluminum sample pan which was immediately sealed. An empty sample pan was used as reference. The samples were heated from 25 to $250{ }^{\circ} \mathrm{C}$ at a rate of $10{ }^{\circ} \mathrm{C}$ using DSC equipment (DSC822e, Mettler Toledo). Nitrogen gas was utilized to flush the DCS cell at a flow rate of $10 \mathrm{~mL} / \mathrm{min}$ to maintain an inert condition. The transition temperatures were calculated from the thermogram results.

A thermogravimetric analysis (TGA) was conducted to study the thermal behavior of blends. The thermal behavior was registered on a TA Instrument TGA Q50 thermogravimetric analyzer. The samples of $\sim 5 \mathrm{mg}$ were heated of $25^{\circ} \mathrm{C}$ up to $600{ }^{\circ} \mathrm{C}$ at a rate of $10^{\circ} \mathrm{C} \mathrm{min}^{-1}$. A constant nitrogen flow rate of $10 \mathrm{~mL} \mathrm{~min}{ }^{-1}$ was employed, which supplied an inert atmosphere during the pyrolysis and allowed extracting the gaseous and condensable products that could cause secondary interactions in vapor phase.

Tensile tests of the sheets were carried out according to ASTM D882-12 standard, by using a Universal Testing Machine (UTM) Instron Tecsis 4468, equipped with a load cell of $45 \mathrm{kN}$ and a traction speed of $5 \mathrm{~mm} / \mathrm{min}$. The tensile test were performed at $20^{\circ} \mathrm{C}$ and $50 \%$ RH. Data were subjected to analysis of variance (ANOVA) to determine statistical differences. Hydrolytic degradation was evaluated in buffer solutions (Hanna instruments) at three different $\mathrm{pH}: 4,7$, and 10. Sheets were cut into rectangular shaped samples (weight $\sim 100 \mathrm{mg}$ ) and placed into test-tubes with the solution at $\mathrm{pH} \mathrm{4,} \mathrm{7,} \mathrm{or} \mathrm{10,}$ maintaining the ratio sample/solution medium at 1/100 in mass in all tests. Every $24 \mathrm{~h}$ the samples were taken out of the buffer solutions, washed with distilled water, gently wiped with paper, dried at ambient temperature and subsequently weighed. 
Soil burial degradation tests was carried out as second method to evaluate degradation of the samples. The tests were executed in exterior soil conditions in the campus of the BíoBío University, Concepción, Chile. Samples (150 x 30 x $1 \mathrm{~mm})$ were dried at $105^{\circ} \mathrm{C}$ for $24 \mathrm{~h}$ and weighed to obtain the initial mass. Samples were buried at $10 \mathrm{~cm}$ depth in soil which was regularly moistened with distilled water. Iron mesh was used to wrap the samples before buried into the soil to facilitate removal of the degraded samples while maintaining the access of moisture and microorganism. Samples were taken from the soil at predetermined intervals of 7 and 14 days and gently cleaned with distilled water to remove impurities. Finally, the samples were dried at $105^{\circ} \mathrm{C}$ for $24 \mathrm{~h}$ and weighed to obtain the final mass. Both degradation methods were performed taking five samples of each material. The degradation process was followed by determining the mass loss of the materials according the following equation:

$$
\text { Weight Loss }(\%)=\left(\mathrm{W}_{\mathrm{i}}-\mathrm{W}_{\mathrm{dry}}\right) / \mathrm{W}_{\mathrm{i}} \times 100
$$

Where $\mathrm{W}_{\mathrm{i}}$ was the initial weight of the sample at zero degradation time and $\mathrm{W}_{\text {dry }}$ was the dried weight of the sample at the specific time of degradation. An analytical balance (AND GR-202) with sensitivity of $0.1 \mathrm{mg}$ was used to weigh the samples.

\section{RESULTS AND DISCUSSION}

In this work the initial liquefaction conditions (weight ratio of G:SA of 100:3; reaction temperature: $180^{\circ} \mathrm{C}$; reaction time $60 \mathrm{~min}$; ratio of 0.25 of mass/liquefying solvent (w/v)) for the tests were selected by considering the results obtained in the recent work by our group [15]. For evaluating the possibilities of glycerol liquefaction of corn husks into a 
liquid form, the effect of liquefaction temperature and time (Fig. 1) has been preliminary investigated.

\subsection{Effect of temperature and reaction time on the liquefaction yield.}

The effect of the reaction temperature on the liquefaction yield is shown in Fig.1a. Liquefaction conditions of the samples were set at a mass/solvent ratio of 0.25 , weight ratio G:SA of 100:3 and a reaction time of $60 \mathrm{~min}$.

The liquefied corn husks reached a yield of $84 \%$, $89 \%$, $92 \%, 90 \%$ and $89 \%$ for 130, 140, 150, 160 and $170{ }^{\circ} \mathrm{C}$, respectively. The optimum liquefaction yield (92\%) was reached at $150{ }^{\circ} \mathrm{C}$. At a temperature of $170{ }^{\circ} \mathrm{C}$, the reaction becomes into a repolymerization reaction of the different liquefied components. That produces a deceleration on the liquefaction reaction rate, giving as a result a higher amount of residue. Thus, lower reaction temperature drives to proper liquefaction conversion values and also implies an economical advantage for the process due to the reduction on the energy requirements. Therefore, the liquefaction temperature of $150{ }^{\circ} \mathrm{C}$ is established as the most suitable process temperature.

On the other hand, liquefaction of corn husk residues carry out at five different reaction times is also shown in Fig. 1b. The experiments considered a mass to liquefying solvent ratio of 0.25 by using weight ratio G:SA of $100: 3$ and temperature of $150{ }^{\circ} \mathrm{C}$. The liquefaction yield reached 84 \%, $95 \%$, $99 \%, 97 \%$ and $96 \%$ for 30, 40, 45, 50 and 60 min, respectively. 
At 30 min the yield obtained was quite low. A correct liquefaction reaction took place at 45 min of reaction with a yield of $99 \%$. During the corn husk residues liquefaction both degradation and re-polymerization reactions coexist. In the degradation process the decomposition of corn husk takes place and the residue fraction is reduced. On the contrary during the re-polymerization reaction, the residue fraction is increased and an insoluble material is generated. In our study, an increase on time from 30 to 45 min under the liquefaction conditions established, improved the liquefaction effect due to the prevalence of degradation phenomena. So, the results show that a range of liquefaction reaction time from 40 to $60 \mathrm{~min}$ is suitable to get high conversion values above $95 \%$ of the corn husks liquefaction process.

\subsection{Infrared Spectroscopy analysis}

Infrared spectroscopy analysis was used to study the change of component of the corn husk in the liquefaction reaction. Fig. 2 shows an increase in the peaks intensities of liquefied product compared to the raw material, which indicates the success of liquefaction reaction. The band at $1730 \mathrm{~cm}-1$ in corn husk curve is attributed to the stretching vibration of $\mathrm{C}=\mathrm{O}$ in hemicelluloses. This band disappeared in liquefied product curve, which indicates that hemicelluloses are fully liquefied at the end of the reaction. In addition, with the purpose of verifying modifications in the chemical composition of the liquefied product respect to glycerol used as solvent in liquefaction reaction, infrared spectroscopy analysis was performed. Fig. 2 shows FT-IR spectra of Glycerol and liquefied product from corn husks. The broad signal at $3400 \mathrm{~cm}^{-1}$ corresponds to the stretching vibration of hydroxyl groups and therefore it indicates that the liquefied 
product presents $\mathrm{OH}$ groups within its chain. Peaks at $2900 \mathrm{~cm}^{-1}$ and at $1455 \mathrm{~cm}^{-1}$ refer to the $-\mathrm{CH}_{2}$ vibration band and to $\mathrm{C}-\mathrm{H}$ deformations, respectively. Peaks were observed at 1220 and $1080 \mathrm{~cm}^{-1}$ coincide with C-O ether oscillations. Besides these general signals, the spectrum also revealed others bands that indicate the presence of functional groups derived from the degradation of cellulose, hemicelluloses and lignin in the liquefied product. The spectrum of the liquefied product revealed that at $1712 \mathrm{~cm}^{-1}$ appeared a new band that could be addressed to a $\mathrm{C}=\mathrm{O}$ stretching of esters. During the liquefaction process in the presence of sulphuric acid, carboxyl groups from the biomass and the glycol

molecules reacted, generating ester groups by an esterification reaction (Kurimoto et al., 2000). Hemicelluloses from the biomass have in their structure carboxyl groups which are formed by the oxidation process of carbohydrates and lignin. Lignin is likely to be alcolyzed by an alcoholysis reaction (Kurimoto et al., 2000), which implies the presence of aromatic rings in the liquefied product. In this regard, aromatic skeletal vibrations of $\mathrm{C}-\mathrm{C}$ in lignin appear at $1604 \mathrm{~cm}^{-1}$ in the liquefied product spectrum meaning the presence of aromatic rings in the product molecular structure. At $825 \mathrm{~cm}^{-1}$ the spectrum also showed other bands corresponded to guaiacyl units.

\subsection{Characteristic of liquefied products}

In order to characterized the suitability of the obtained liquefied products as biopolyols to be considered as new environmentally friendly additives for polymeric starch blends, the properties of the liquefied products have been studied. Corn husk residue has higher celluloses and hemicelluloses content, which may cause lower amount of residue or high liquefaction yield when this agricultural biomass is used. The final viscous product from 
the corn husk liquefaction process using glycerol, which reaction consists mainly on an alcoholysis process, has numerous hydroxyl groups on its composition. Glycerol and the hydroxyl groups would react with each other giving as a result a derivative molecule with an ether bond to be finally dissolved in the rest of the remaining glycols. Table 1 shows the liquefied sample properties. Comparing the results obtained herein and the published data from the literature using different types of raw material for the liquefaction process, our $\mathrm{I}_{\mathrm{OH}}$ value of $310 \mathrm{mg} \mathrm{KOH} / \mathrm{g}$ ) was lower than those prepared from corn residues using similar experimental conditions [biomass: corn stover and corncob, biomass/liquefying solvent ratio (w/v): 0.25, weight ratio PEG\#400:G:SA of 80:20:3, reaction temperature: $180^{\circ} \mathrm{C}$, reaction time: $60 \mathrm{~min}, \mathrm{IOH}: 342-441 \mathrm{mg} \mathrm{KOH} / \mathrm{g}$ [15]]. This could be attributed to the presence of PEG\#400 in liquefying solvent, having high hydroxyl group content. On the contrary, liquefied product viscosity had an average value of 3.4 Pa.s measured at $25{ }^{\circ} \mathrm{C}$. Viscosity values were ranged between 0.33 and 31.6 Pa.s, from variations of the ratio of 0.1 to 0.5 mass/liquefying solvent (w/v) for different Japanese wood flour species investigated by Kurimoto et al.[19,20] by using different liquefaction conditions (PEG:G:SA of $90: 10: 3,150{ }^{\circ} \mathrm{C}, 75 \mathrm{~min}$ ). Taking into account the results obtained, using a glycerol liquefaction reaction, polyols generated are considered as precursors for polymeric materials, due to their suitable $\mathrm{I}_{\mathrm{OH}}$ and viscosity values; $\mathrm{I}_{\mathrm{OH}}$ between 300 and 800 and viscosity below 300 Pa.s [21]

Even being the liquefaction tests performed under anhydrous conditions, results showed a minimal amount of water (moisture) on the samples. Liquefied corn stover showed an average molecular weight $\left(\mathrm{M}_{\mathrm{W}}\right)$ of $549 \mathrm{~g} / \mathrm{mol}$. It has been reported a molecular weight 
value of $3857 \mathrm{~g} / \mathrm{mol}$ by Briones et al.[2] for liquefied corncob residue using a mixture of poly(ethylene glycol) [PEG, with an average molecular weight $\left(\mathrm{M}_{\mathrm{W}}\right)$ value of 400 ] and glycerol, both as solvents, with also $98 \%$ of sulfuric acid as catalyst using similar experimental conditions [biomass/liquefying solvent ratio $(\mathrm{w} / \mathrm{v}): 0.25$, weight ratio PEG:G:SA of 80:20:3, reaction temperature: $160{ }^{\circ} \mathrm{C}$, reaction time: $60 \mathrm{~min}$ ]. Comparing this result with others from similar samples, this situation suggests shorter carbon chains within the liquefied corn stover structure. Also, its molecular distribution was narrower, meaning a lower $\mathrm{M}_{\mathrm{w}} / \mathrm{M}_{\mathrm{n}}$ ratio (polydispersity index) for the final product, which could be considered as a positive issue due to its polymer precursor or additive behaviour. Considering the evaluation of the molecular weight and the FT-IR analysis the liquefied product evaluated can be classified as an oligomeric polyol. Low density value (1.30 $\mathrm{g} / \mathrm{cm}^{3}$ ) could be caused by the lower density of the lignocellulosic raw material. On the other side, $\mathrm{pH}$ and acid number $\left(\mathrm{I}_{\mathrm{AC}}\right)$ for liquefied corn husks were 2.1 (at $25^{\circ} \mathrm{C}$ ) and 28mg KOH/g. Liquefied product exhibited a corresponding acidity value considering the acid medium where the reaction was carried out and the high presence of the organic acids from the modified feedstocks [2]. So, the decomposition of the lignocellulosic material into organic acids throught a thermic oxidation of carbohydrates and lignin could be considered the reason for the high liquefaction yield obtained.

\subsection{Processing properties analysis}

The maximum torque, specific energy, plasticization energy and steady state are presented in Table 2. Specifically, the plasticization energy is calculated as the integral of the torque curve from time zero to maximum torque time [22]. According to Table 2, 
all the rheological properties of the blends were considerably affected by the addition of liquefied product. The greater amount of the liquefied product (biopolyol) was in the mixture, the lower plasticization energies and torque values were obtained. In addition, the values obtained of these properties depended also on the type of the plasticizer employed during the preparation of the blends; in that sense, specific energy and steady state were higher for glycerol (70S30G) blends than for liquefied product ones. In addition, once the polymeric blends were deconstructed, their toque values decreased until the steady state. Lowest values were shown on blends plasticized with liquefied products compared to control ones, which could be explained because acid derivatives present in liquefied product could promote the acid hydrolysis of the glycosidic linkages from the starch, decreasing the molecular weight as well as the degree of polymerization. Similar behaviour of rheological properties were reported by Da Róz et al. and Jiugao et al.[23,24]. On the other hand, in Fig. 3 it is shown the torque variation as a function of time for researched blends. Three different regions can be seen on the torque-rheometer plots as a function of time: an increasing torque until the maximum value attributed to the plasticization process, followed by a consistent decline zone, ending on the steady region area. Similar tendency on variations of torque with time were showed in all blends: a quick increase to reach the maximum value and a gradually decrease after the plateau state. The time required to reach steady state is similar for all samples around $5 \mathrm{~min}$. From literature, the viscosity of the polymer during the melt-blending process and the equilibrium torque are related to each other [25]. Molecular chains mobility due to shear forces and temperature is related to the viscosity of the polymer. As was expected, torque 
rheometer values show that the steady torque of the samples diminishes as liquefied product increases in the composition. Hydrogen bonds from the biopolyol molecules interact with the macromolecules of starch, allowing more mobility of the macromolecules chains. So, when the liquid product is used as plasticizer, the requirements of energy are lower for plasticizing the starch. Once the steady state was reached, the values were almost kept without any variation after 5 mins, indicating that during the processing of the samples there was not any chain degradation, cross linking or loss of plasticizer.

3.5 Micro morphology analysisSEM images of starch granules and the surfaces of sheets samples are exhibited in Fig. 4. After blending, starch granules were not observed in the surface of the sheets due to the processing of starch changing it granular morphology to a continuous phase indicating the starch plasticization under the used processing conditions. Due to the accumulative action of plasticizer, shear rate and processing temperature in the torque-rheometer, starch granules melted or were physically broken up into small fragments, which resulted in homogenous surfaces and disappearance of granular structure of starch. Thus, a continuous phase was observed indicating that there is good compatibility between the components. In that sense, liquefied product used a plasticizer promotes the fragmentation and dissolution of the starch granules as it disrupts the intermolecular and intramolecular hydrogen bonds and plasticizes the starch during processing in the torque-rheometer.

Similar results with glycerol used as plasticizer were obtained by Schmitt et al. [26]. Also, this situation could be ascribed to the heterogeneous nature of liquefied derivatives from 
corn residues liquefaction that was found in an earlier study [15]. Taking into consideration the chemical constitution of the corn husks, the higher cellulose and hemicelluloses content and the lower lignin content could be directly related to the higher homogeneity of the sheet samples.

Hemicelluloses are amorphous structures easily available to the liquefaction solvent producing smaller biomass-derived molecules with high reactivity. According to this, the smaller size of molecules and fragments from cellulose and hemicelluloses derivatives not only are highly reactive with each other and with the liquefaction solvent but also can create appropriate blends with starch, forming sheets with higher level of uniformity. On the other side, the surface of 80S20L sample was smooth with a large amount of cracks, indicating a low liquefied product content used as plasticizer and/or a partial miscibility between the liquefied product and the starch, producing a film with low elasticity promoting cracks after compression molding.

\subsection{Differential scanning calorimetry analysis of blends}

The thermogram of starch and polymer blends is shown in Fig. 5. The pure starch curve indicated the temperature range during heating of amorphous chains to acquire mobility has it peak at $106^{\circ} \mathrm{C}$. The increasing liquefied product content in blends results in materials with amorphous zones where initial transitions occur at lower temperature and heat flow compared to starch.

Plasticizers act in polymeric compounds enhancing their flexibility and processability by decreasing the hydrogen bonding of the polymeric chains, which leads to an increasing free volume or molecular mobility of polymers [27]. The relationship of starch content 
to peak transition is not linear, as the peak for 60,70 and $80 \%$ starch blends occur at 98 , 101 and $105^{\circ} \mathrm{C}$. The glass transition temperature (Tg) of starch films has been reported at different temperatures from -20 till $127^{\circ} \mathrm{C}$ and even higher depending of the starch type, its possible modification, plasticizer type and content and the conditions of the storage $[28,29]$. On the other hand, melt temperature is one of the key variables in polymer extrusion which determines process thermal stability and hence melt quality [30]. Fig. 5 shows that up to $200^{\circ} \mathrm{C}$ blends presents endothermic peaks referred to the melting of decomposition of liquefied biomass derivatives mainly. The relationship of liquefied product content to the peak melting point is not linear, as the peak for 40,30 and $20 \%$ biopolyol blends occur at 227, 221 and $211{ }^{\circ} \mathrm{C}$ respectively. There is also a difference in the type of crystallinity between the three samples where $60 \%$ starch mixture has a tall and narrow profile, whereas the $80 \%$ starch has a much wider and shorter crystallization curve. This can most likely be attributed to the lack of availability of the plasticizing liquefied product. Therefore, it can be stated that the incorporation of liquefied products into starch blends increased the melting temperature $\left(T_{m}\right)$ in comparison to the values of the control sample. The increase of Tm values in blends with the liquefied product comparing to the control film can be assigned to the interactions among the liquefied lignocellulosic components and the starch. The thermoplastic starch is a very fragile material. Furthermore, the increase of melting temperature when liquefied product is added in the starch blends could be an indication of improved elasticity and plasticity (increased strain).

\subsection{Thermogravimetric analysis of blends}


Fig.6 indicates the conditions of the thermogravimetric analysis up to $600{ }^{\circ} \mathrm{C}$ showing the thermogravimetry curve (mass loss as a function of Temperature, TG) and derivative thermogravimetry curve (weight loss rate, DTG) under $\mathrm{N}_{2}$ atmosphere for the starch, the liquefied product and their blends samples. A similar thermal degradation behavior was observed in the different types of blends. Each curve showed a weight loss at three regions during the analysis. For instance, in the profile corresponding to $30 \%$ of the liquefied product content in the blend $70 \mathrm{~S} 30 \mathrm{~L}$, peaks from 110 to $175^{\circ} \mathrm{C}$ observed in the DTG curve were produced by the humidity loss together with the evaporation of low molecular weight compounds of liquefied product and probably the decomposition of extractable compounds present in corn residues. Furthermore, two main zones of weight loss were identified during the thermal degradation stage which may be attributed not only to the defragmentation of the dissolved lignocellulosic components and to the degradation of the liquefied compounds, but also to the decomposition of the starch used as matrix to prepare the blends. The behavior of the pyrolysis process of the biomass can be synthesized as the sum of the behavior of the three major components during the pyrolysis process; hemicelluloses degrade from 200 to $250^{\circ} \mathrm{C}$, cellulose from 240 to $320^{\circ} \mathrm{C}$ and lignin range started at 280 to higher than $400{ }^{\circ} \mathrm{C}[31]$. In this context, the second weight loss zone corresponded to a broad peak from 175 to $320^{\circ} \mathrm{C}$ that could be attributed mainly to the decomposition of starch and the liquefied corn husks fragments triggered by hemicelluloses and cellulose resulted in the weight loss rate with the peak at $250^{\circ} \mathrm{C}$. The third weight loss zone took place in a broad peak ranging from 320 to $480{ }^{\circ} \mathrm{C}$ that could be attributed to the fragmentation of liquefied corn compounds from the cellulose and 
lignin resulted in the weight loss rate of the peak at $400{ }^{\circ} \mathrm{C}$. It is worth noting that this last zone was not observed in TGA/DTG curves of starch, confirming the presence of lignin degradation components in the blends. Liquefied corn husks and starch showed their most important weight loss rate at $200{ }^{\circ} \mathrm{C}$ and $320^{\circ} \mathrm{C}$, respectively at the same TGA conditions that blends were assessed.

This peak shifted to lower temperatures in all blends, indicating that the liquefied product used as plasticizer decreases the thermal stability of starch in that region. Again it is worth mentioning that blend samples revealed profiles with comparable thermal trends. In fact, under $310^{\circ} \mathrm{C}$ the degradation of blends was higher in comparison to the starch at the same temperature. It could be related to the presence of dissolved lignocellulosic components. However, from 310 to $410{ }^{\circ} \mathrm{C}$ a change on the tendency was noticed; blends exhibited lower decomposition than the starch sample which could be possibly associated to the formation of condensed aromatic structures that slow down the thermal degradation processes until their complete degradation. Eventually, total weight loss for blends was measured at around $85-90 \%$ at temperature range from 25 to $600^{\circ} \mathrm{C}$. The thermal stability of blends using liquefied products can be assigned to the strong interfacial interactions among lignocellulosic liquefied components. Having regard to the above, the following studies present the analysis of blends elaborated with a content of $30 \%$ of liquefied product used as plasticizer, considering this product had better performance in processing and thermal properties, required characteristics for polymer processing applications.

\subsection{Tensile properties analysis}


Representative stress-strain curves for sheets with 20 and $30 \%$ of liquefied product contents (80S20L; 70S30L) and control sheet with glycerol (30\%) are shown in Fig7. The samples present a typical stress-strain behavior of plasticized starch blends in which the lowest part of the curve showed an elastic behavior with very lower deformations, followed by a plastic zone until sample rupture. Sample 80S20L showed short zones of elastic and plastic deformation and then the break due to the low amount of plasticizer and the presence of starch grains that act as fissure propagators. Sample 70S30L showed a similar behavior in the elastic zone compared to the control sample, but presented more range of plastic region before failure.

Summarized results of Young's modulus, strain at break and tensile strength values are shown in Table 3. According to Table 3, all the mechanical properties of sheets were significantly affected by the addition of liquefied product. 80S20L and 70S30L displayed greater values of modulus than 70S30G. For instance, 70S30L reached an average value of $14 \mathrm{MPa}$ of the Young's modulus showed an increase around $60 \%$ in comparison to control sample, exhibiting a greater stiffness for low strains.

This situation could be explained probably as a result of the presence of lignocellulosic degradation components in the liquefied product, acting as reinforcing load, increasing the elastic modulus. In this context, liquefied product, which contains degradation products of cellulose and lignin components confirmed preliminary by FT-IR analysis, resulting in a polyol that had a reinforcing effect when is incorporated into blends compared to control sample. In addition, higher value of strain at break (33 \%) were noted in 70S30L with an increase of $40 \%$ approximately compared to the results obtained for 
control sample, which is attributed to the plasticized effect of the liquefied product, softening the structure by increasing the mobility of the starch's macromolecules and therefore reducing the maximum tensile strength, making of this film with more ductile behavior due to a probable increase of the amorphous regions of the material. This situation allows estimating that liquefied product act as a better plasticizer for the starch than glycerol under test conditions of this study. Similar results in mechanical properties for starch based composites plasticized with glycerol elaborated by compression molding method had been reported by several authors [25,32,33], considering the starch type, its eventual modification, plasticizer type and content and the conditions of storage.

\subsection{Hydrolytic Degradation results}

The hydrolytic degradation was performed on sheets (70S30L) and on the control sheet using glycerol as plasticizer (70S30G) at different pH solutions (4, 7 and 10). Fig. 8 shows the weight loss at $\mathrm{pH} \mathrm{4,} 7$ and 10 , measured at $22^{\circ} \mathrm{C}$ during 120 hours. In the hydrolytic degradation, polymer bonds react with the water molecules, particularly the chemical bonds in the amorphous phase and transforming long polymer chains into shorter ones. For both types of sample the degradation tests revealed that the weight loss rate is faster at $\mathrm{pH} 10$ during the first 48 hours and also, at this $\mathrm{pH}$ the 70S30L sample show the highest degradation rate. This behavior could be explained due to the high presence of organic acids derivatives characteristic of modified raw materials producing during biomass liquefaction. It is expected that liquefied product were formed by mainly carboxylic acids, carbohydrates and lignin derivatives compounds. At $\mathrm{pH}>4$, the dissociated form of the liquefied product predominates which accelerates the hydrolysis while at $\mathrm{pH}<4$ the 
liquefied product at the chain ends stays at the associated form. On the other hand, this behavior could be explained because liquefied product resultingfrom liquefaction of lignocellulosic biomass could be more hydrophilic than glycerol, due to the presence of a large number of oxygen-containing reactive functional groups that are compounds of cellulose, hemicelluloses and lignin constituents, favors the absorption of water. Moreover, the biodegradation characteristics of the materials can be observed and measured by the weight loss due to the moisture and the microorganism activity during the soil burial period. Fig. 8 also indicates the weight loss of sheets with 30\% of liquefied product (70S30L) and 30\% of glycerol after soil burial for 1 and 2 weeks, respectively. Similar tendency was observed in soil burial tests respect to weight loss compared to hydrolytic tests. Both type of sheets exhibited a smooth and homogeneous surfaces morphology before been tested. However, sings of degradation were observed at the first week in both samples becoming deformed and rougher surfaces. Loss of flexibility was observed in both films principally due to the migration from the matrix to the surface of plasticizers used. This situation could be explained because the plasticizer would eventually be adsorbed by soil or passed through the starch cell membrane, being metabolized by microbes and increased the weight loss of the sheets [34]. Higher weight loss was observed in sheet samples with liquefied product used as plasticizer compared to sheets with glycerol, where 70S30L shows the highest at $47 \%$ and $85 \%$ after 1 and 2 weeks of burial, respectively. After the second week of been buried, 70S30L sample showed more fragile for at touch and mostly fragmented, having a higher weight loss compared with control one, with 70\%. According to Maran et al.[34], increase in 
hygroscopic features of material will promote the growth of microorganisms during degradation and increases the weight loss of material. Therefore, liquefied product presented a strong hydrophilic character compared to glycerol when was used as plasticizer in blends, which favored the absorption of water, increased the water activity of sheets and promoted the growth of microorganisms.

\section{CONCLUSION}

The use of glycerol in a biomass liquefaction reaction produced interesting properties on the resulted biopolyols and blends. Corn husks liquefaction was very effective by an acidcatalyzed reaction, with lower molecular weights, suitable IoH and viscosities values of the biopolyols. The potential of liquefied corn husks obtained through liquefaction process have been successfully demonstrated by their use in the preparation of starch/biopolyol blends and sheets. Starch/biopolyol blends and sheets had enhanced features compared with the control sample plasticized by glycerol, allowing the production of homogeneous and miscible dark brown blends presenting appropriated thermal and processing characteristics. The incorporation of liquefied products into blends and sheets increased the Young modulus, strain at break, tensile strength and degree of biodegradability in comparison to control sample. This could be assigned to the existence of degraded lignocellulosic derived compounds that improve physical and mechanical properties, opening opportunities in bioplastics. Indeed, there are interesting possibilities of using the blends evaluated as raw material in polymer processing such as extrusion process for pellets and film elaboration to obtain bio-based composites for 
agrarian activities. Moreover its use as an option to petroleum based products. Is highly relevant and warrants continued development.

\section{AUTHOR FOR CORRESPONDENCE}

\section{Corresponding Author}

Rodrigo Briones

*E-mail: r.briones@cipachile.cl

\section{ACKNOWLEDGMENTS}

The authors thanked to the Chilean' National Commission for Scientific and Technological Research [CONICYT Fondecyt Iniciación /cod. 11160914; CONICYT Programa de Cooperación Internacional/REDES180165] for financially supporting this research.

\section{REFERENCES}

1 Wang C, Pan J, Li J, Yang Z, Comparative studies of products produced from four different biomass samples via deoxy-liquefaction. Bioresour. Technol. 99, 2778-2786 (2008).

2 Briones R, Serrano L, Sequeiros A, Labidi J, Influence of microwave heating on chemical properties of liquefied lignocellulosic residues. Ind. Eng. Chem. Res. 52, 2755-2761 (2013).

3 Liang L, Mao Z, Li Y, Wan C, Wang T, Zhang L, Zhang L, Liquefaction of Crop Residues for Polypol Production. BioResources 1, 1-9 (2006).

$4 \quad$ Wang H, Chen HZ, A novel method of utilizing the biomass resource: Rapid liquefaction of wheat straw and preparation of biodegradable polyurethane foam 
(PUF). J. Chinese Inst. Chem. Eng. 38, 95-102 (2007).

5 Hassan EM, Shukry N, Polyhydric alcohol liquefaction of some lignocellulosic agricultural residues. Ind. Crops Prod. 27, 33-38 (2008).

6 Yan Y, Hu M, Wang Z, Kinetic study on the liquefaction of cornstalk in polyhydric alcohols. Ind. Crops Prod. 32, 349-352 (2010).

$7 \quad$ Yan Y, Pang H, Yang X, Zhang R, Liao, B, Preparation and Characterization of Water-BlownPolyurethane Foams from Liquefied Cornstalk Polyol. J. Appl. Polym. Sci. 110, 1099-1111 (2008).

8 Chen F, Lu Z, Liquefaction of Wheat Straw and Preparation of Rigid Polyurethane Foam from the Liquefaction Products. J. Appl. Polym. Sci. 111, 508-516 (2009).

9 Gao LL, Liu YH, Lei H, Peng H, Ruan R, Preparation of Semirigid Polyurethane Foam with Liquefied Bamboo Residues. J. ofAppliedPolymer Sci. 116, 16941699 (2010).

10 Briones R, Serrano L, Labidi J, Valorization of some lignocellulosic agroindustrial residues to obtain biopolyols. J. Chem. Technol. Biotechnol. 87, 244249 (2012).

11 Hu S, Wan C, Li Y, Production and characterization of biopolyols and polyurethane foams from crude glycerol based liquefaction of soybean straw. Bioresour. Technol. 103, 227-233 (2012).

$12 \mathrm{Hu}$ S, Li Y, Polyols and polyurethane foams from base-catalyzed liquefaction of lignocellulosic biomass by crude glycerol: Effects of crude glycerol impurities. 
Ind. Crops Prod. 57, 188-194 (2014).

$13 \mathrm{Hu}$ S, Li Y, Two-step sequential liquefaction of lignocellulosic biomass by crude glycerol for the production of polyols and polyurethane foams. Bioresour. Technol. 161, 410-415 (2014).

14 Werpy T, Petersen G, Top value added chemicals from biomass. Volume I; U.S. Department of Energy; Pacific Northwest National Laboratory (PNNL) and National Renewable Energy Laboratory (NREL); Golden, CO: Washington DC, 2004.

15 Briones R, Torres L, Saravia Y, Serrano L, Labidi J, Liquefied agricultural residues for film elaboration. Ind. Crops Prod. 78, 19-28 (2015).

16 TAPPI Standards, in TAPPI Test methods, Atlanta. GA (2007).

17 Rowell R, The Chemistry of Solid Wood. Advances in Chemistry Series, American Chemical Society, Washington DC, pp 70-72 (1983).

18 American Society for Testing and Materials (ASTM), in Standard Test Method for Acid and Base Number by Color-indicator Titration. ASTM, Pennsylvania, D974 (2008).

19 Kurimoto Y, Koizumi A, Doi S, Tamura Y, Ono H, Wood species effects on the characteristics of liquefied wood and the properties of polyurethane films prepared from the liquefied wood. Biomass and Bioenergy 21, 381-390 (2001).

20 Kurimoto Y, Takeda M, Doi S, Tamura Y, Ono H, Network structures and thermal properties of polyurethane films prepared from liquefied wood. Bioresour. Technol. 77(1), 33-40 (2001). 
21 Cateto CA, Barreiro MF, Rodrigues AE, Belgacem MN, Optimization study of lignin oxypropylation in view of the preparation of polyurethane rigid foams. Ind. Eng. Chem. Res. 48, 2583-2589 (2009).

22 Córdoba A, Cuéllar N, González M, Medina J, The plasticizing effect of alginate on the thermoplastic starch/glycerin blends. Carbohydr. Polym. 73, 409-416 (2008).

23 Jiugao $\mathrm{Y}$, Ning W, Xiaofei $\mathrm{M}$, The effects of citric acid on the properties of thermoplastic starch plasticized by glycerol. Starch/Staerke 57, 494-504 (2005).

24 Da Róz AL, Zambon MD, Curvelo AAS, Carvalho AJF, Thermoplastic starch modified during melt processing with organic acids: The effect of molar mass on thermal and mechanical properties. Ind. Crops Prod. 33, 152-157 (2011).

25 Castaño J, Rodríguez-Llamazares S, Carrasco C, Bouza R, Physical, chemical and mechanical properties of pehuen cellulosic husk and its pehuen-starch based composites. Carbohydr. Polym. 90, 1550-1556 (2012).

26 Schmitt H, Guidez A, Prashantha K, Soulestin J, Lacrampe MF, Krawczak P, Studies on the effect of storage time and plasticizers on the structural variations in thermoplastic starch. Carbohydr. Polym. 115, 364-372 (2015).

27 Bertolini A. Starches Characterization, Properties, and Applications. 2009.

28 Lazaridou A, Biliaderis CG, Thermophysical properties of chitosan, chitosanstarch and chitosan-pullulan films near the glass transition. Carbohydr. Polym. 48, 179-190 (2002).

29 Mali S, Grossmann MVE, García MA, Martino MN, Zaritzky NE, Effects of 
controlled storage on thermal, mechanical and barrier properties of plasticized films from different starch sources. J. Food Eng. 75, 453-460 (2006).

30 Abeykoon C, Martin PJ, Kelly AL, Brown EC, A review and evaluation of melt temperature sensors for polymer extrusion. Sensors Actuators, A Phys. 182, 1627 (2012).

31 Wegener DF and G. 1989 Wood-chemistry, ultrastructure, reactions.

32 Domene-López D, Guillén MM, Martin-Gullon I, García-Quesada JC, Montalbán MG, Study of the behavior of biodegradable starch/polyvinyl alcohol/rosin blends. Carbohydr. Polym. 202, 299-305 (2018).

33 Mendes JF, Paschoalin RT, Carmona VB, Sena Neto AR, Marques ACP, Marconcini JM, Mattoso LHC, Medeiros ES, Oliveira JE, Biodegradable polymer blends based on corn starch and thermoplastic chitosan processed by extrusion. Carbohydr. Polym. 137, 452-458 (2016).

34 Maran JP, Sivakumar V, Thirugnanasambandham K, Sridhar R, Degradation behavior of biocomposites based on cassava starch buried under indoor soil conditions. Carbohydr. Polym. 101, 20-28 (2014). 


\begin{tabular}{|c|c|c|c|c|c|c|c|c|c|c|}
\hline Sample & $\begin{array}{c}\text { Yield } \\
(\%)\end{array}$ & $\begin{array}{l}\text { Density } \\
\left(\mathrm{g} / \mathrm{cm}^{3}\right)\end{array}$ & $\begin{array}{c}\text { pH } \\
\left(25^{\circ} \mathrm{C}\right)\end{array}$ & $\begin{array}{c}\text { IOH } \\
\text { (mg KOH/g) }\end{array}$ & $\begin{array}{c}\mathrm{I}_{\mathrm{AC}} \\
(\mathrm{mg} \mathrm{KOH} / \mathrm{g})\end{array}$ & $\begin{array}{c}\text { Viscosity } \\
\text { (Pa.s) }\end{array}$ & $\begin{array}{c}\text { H } \\
(\%)\end{array}$ & $\begin{array}{c}\text { Mw } \\
\text { (g/mol) }\end{array}$ & $\begin{array}{c}\text { Mn } \\
\text { (g/mol) }\end{array}$ & Mw/Mn \\
\hline L18.b & $99 \pm 0,04$ & $1.30 \pm 0.060$ & $2.1 \pm 0.02$ & $310 \pm 11$ & $28 \pm 0.4$ & $3.4 \pm 07$ & 0.75 & 549 & 283 & 1.9 \\
\hline
\end{tabular}

Table 1. Characteristics of the resulting liquefied product from corn husks (weight ratio G:SA of 100:3; temperature: $150^{\circ} \mathrm{C}$; reaction time: $\left.45 \mathrm{~min}\right)$. 


\begin{tabular}{ccccc}
\hline & Torque & Specific & Plasticization & Steady \\
Sample & Maximum & Energy & Energy & state $(\mathbf{N m})$ \\
& $\mathbf{( N m )}$ & $\mathbf{( K N m / K g )}$ & $\mathbf{( N m / m i n )}$ & \\
\hline 60S40L & $3.4 \pm 0.4^{\mathrm{a}}$ & $53.6 \pm 3.8^{\mathrm{a}}$ & $1.7 \pm 0.3^{\mathrm{a}}$ & $0.3 \pm 0.01^{\mathrm{a}}$ \\
70S30L & $8.2 \pm 0.2^{\mathrm{b}}$ & $121.8 \pm 2.8^{\mathrm{b}}$ & $2.4 \pm 0.1^{\mathrm{a}}$ & $1.1 \pm 0.02^{\mathrm{b}}$ \\
80S20L & $15.1 \pm 0.8^{\mathrm{c}}$ & $435.5 \pm 3.1^{\mathrm{c}}$ & $9.1 \pm 0.3^{\mathrm{b}}$ & $4.4 \pm 0.04^{\mathrm{c}}$ \\
70S30G & $18.1 \pm 1.0^{\mathrm{d}}$ & $594.1 \pm 4.6^{\mathrm{d}}$ & $4.9 \pm 0.8^{\mathrm{c}}$ & $8.6 \pm 0.07^{\mathrm{d}}$
\end{tabular}

Table 2. Rheological properties of blends.

Values correspond to average and standard deviations of the rheological properties. Two consecutive letters of the same type show that values are not statistically significant $(p<0.05)$ using Turkey test. Different letters indicate that the averaged values are statistically different at the same level of significance $(\mathrm{p}<0.05)$. 


\begin{tabular}{cccc}
\hline & $\begin{array}{c}\text { Young's } \\
\text { modulus }\end{array}$ & Strain at & Tensile \\
& break & strength \\
Sample & $\mathbf{( M P a )}$ & $\mathbf{( \% )}$ & $\mathbf{( M P a )}$ \\
\hline 80S20L & $18.1 \pm 0.60^{\mathrm{a}}$ & $10.7 \pm 0.80^{\mathrm{a}}$ & $0.9 \pm 0.10^{\mathrm{a}}$ \\
70S30L & $14.0 \pm 0.15^{\mathrm{b}}$ & $33.3 \pm 0.73^{\mathrm{b}}$ & $1.2 \pm 0.10^{\mathrm{b}}$ \\
70S30G & $8.4 \pm 0.94^{\mathrm{c}}$ & $25.7 \pm 1.01^{\mathrm{c}}$ & $0.8 \pm 0.02^{\mathrm{a}}$
\end{tabular}

Table 3. Mechanical properties of sheets.

Values correspond to average and standard deviations of the mechanical properties. Two letters of the same type show that values are not statistically significant $(\mathrm{p}<0.05)$ using Turkey test. Different letters indicate that the averaged values are statistically different at the same level of significance $(\mathrm{p}<0.05)$. 

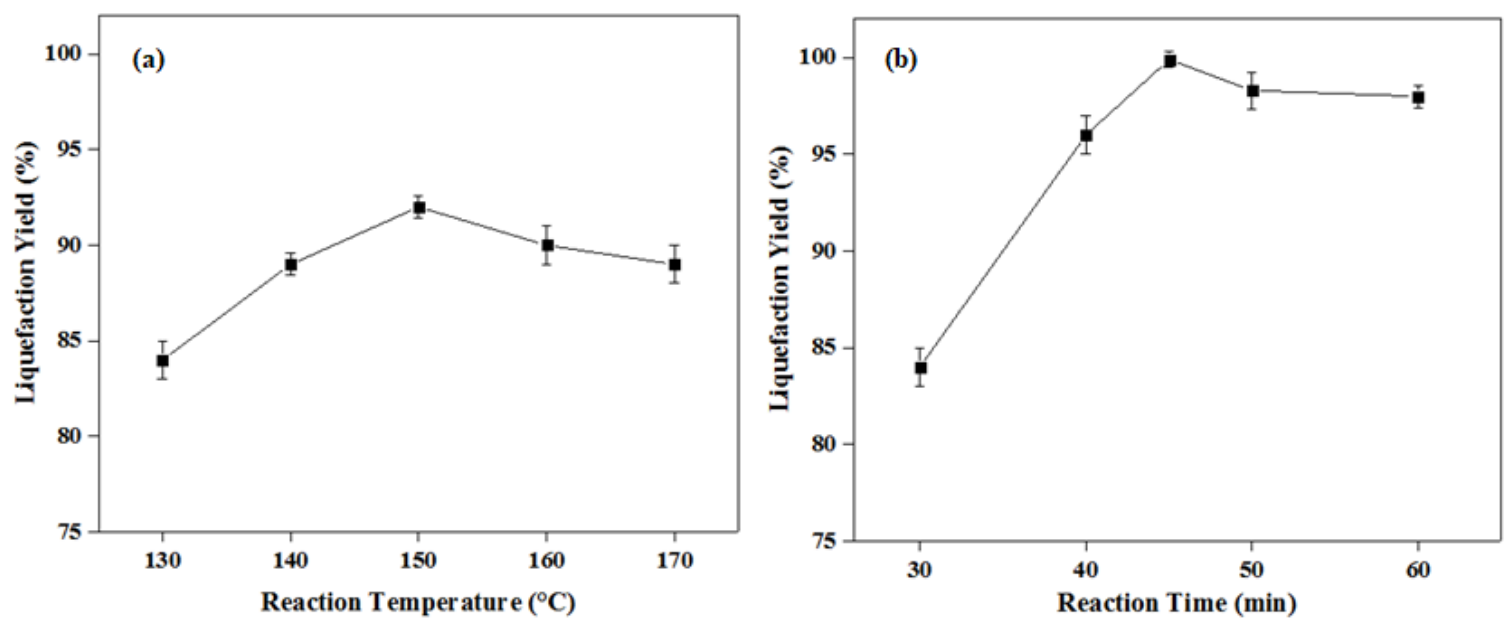

Fig 1. Yield variation (a) Effect of temperature on the liquefaction. Mass/solvent ratio: 0.25; weight ratio G:SA of 100:3; reaction time: $60 \mathrm{~min}$. (b) Effect of reaction time on the liquefaction. Mass/solvent ratio: 0.25; weight ratio G:SA of 100:3; reaction temperature: 150 min. 


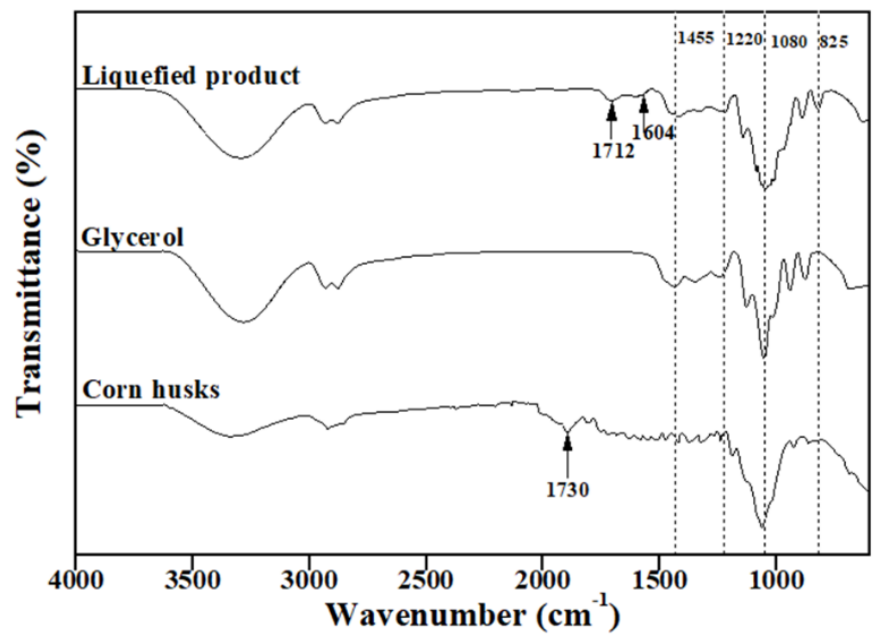

Fig 2. FTIR spectra of corn husks, liquefied corn husks (Mass/solvent ratio: 0.25; weight ratio G:SA of $100: 3$; reaction temperature: $150^{\circ} \mathrm{C}$; reaction time: $45 \mathrm{~min}$ ) and glycerol solvent. 


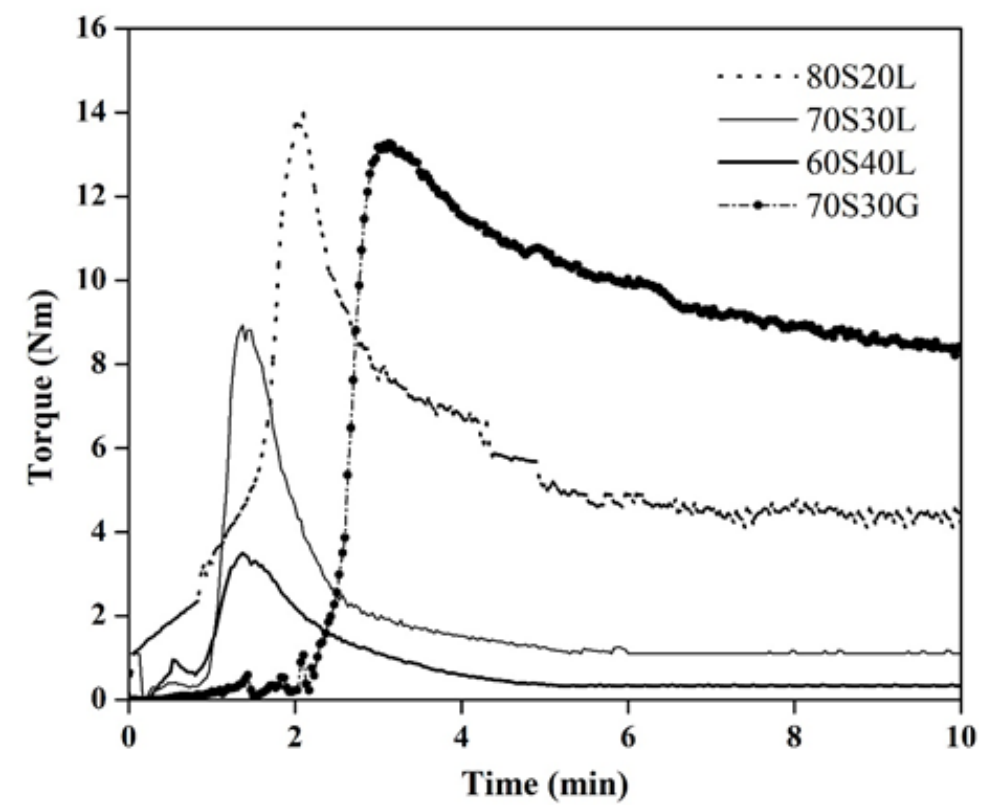

Fig 3. Torque variation as a function of time for comparison of 40, 30 and $20 \%$ biopolyol content in blends samples. 

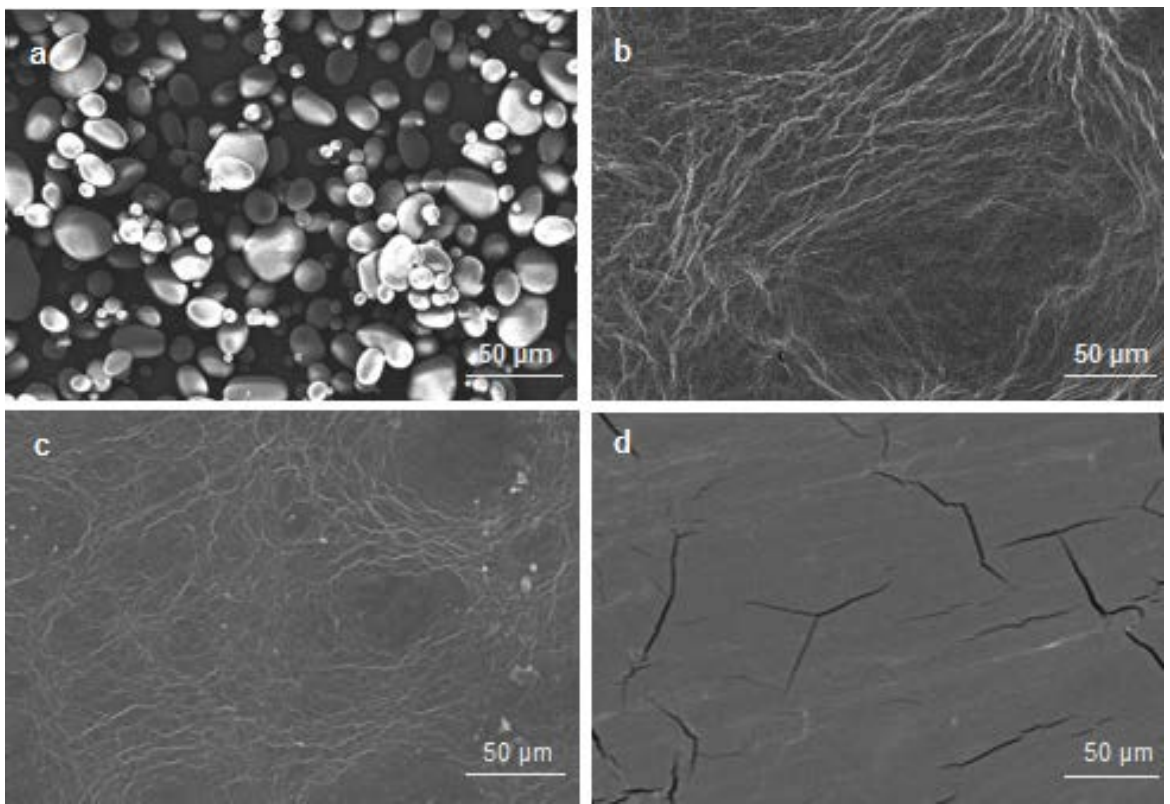

Fig. 4. SEM micrographs of surfaces of blends samples: (a) starch and blends produced with biopolyol in different content, 40\% (b) 60S40L; 30\% (c) 70S30L and 20\% (d) 80S20L. 


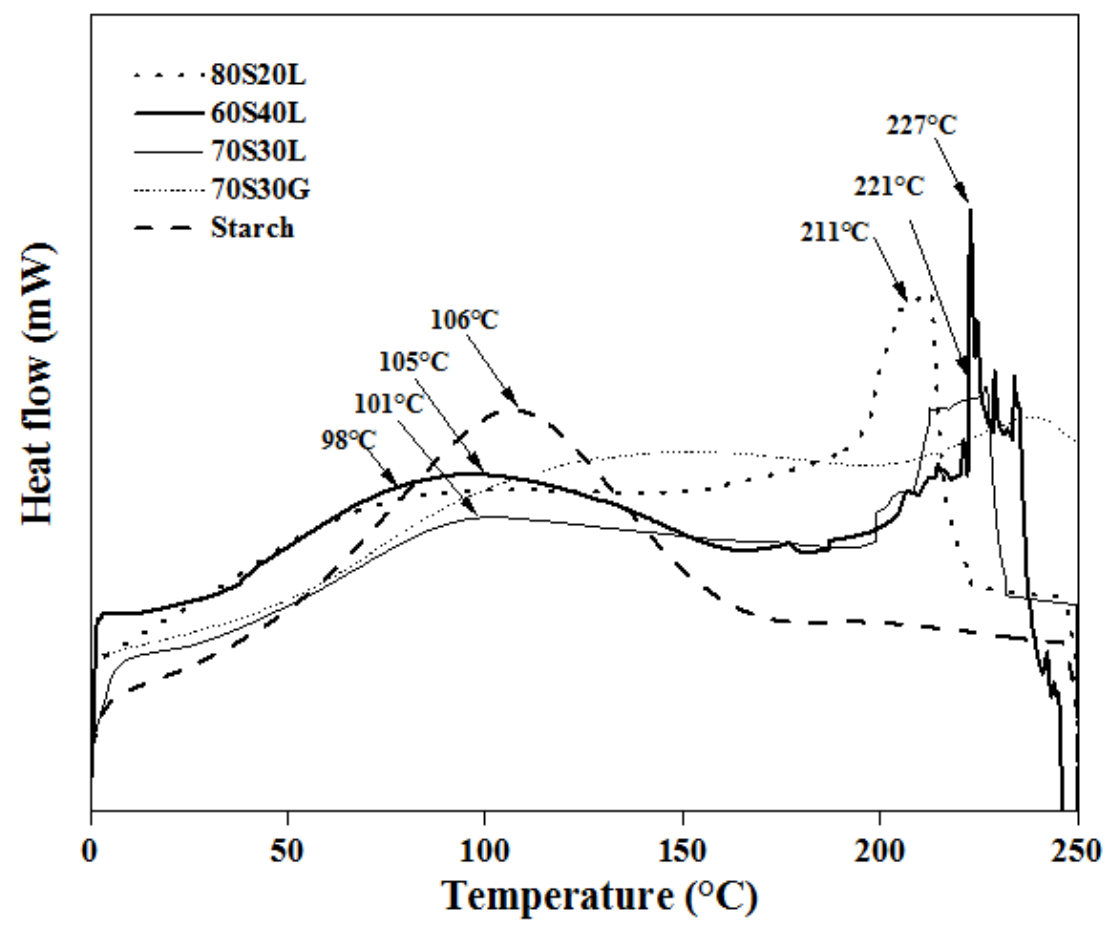

Fig 5. DSC heating curves comparison of 40, 30 and $20 \%$ biopolyol content in blends samples. 

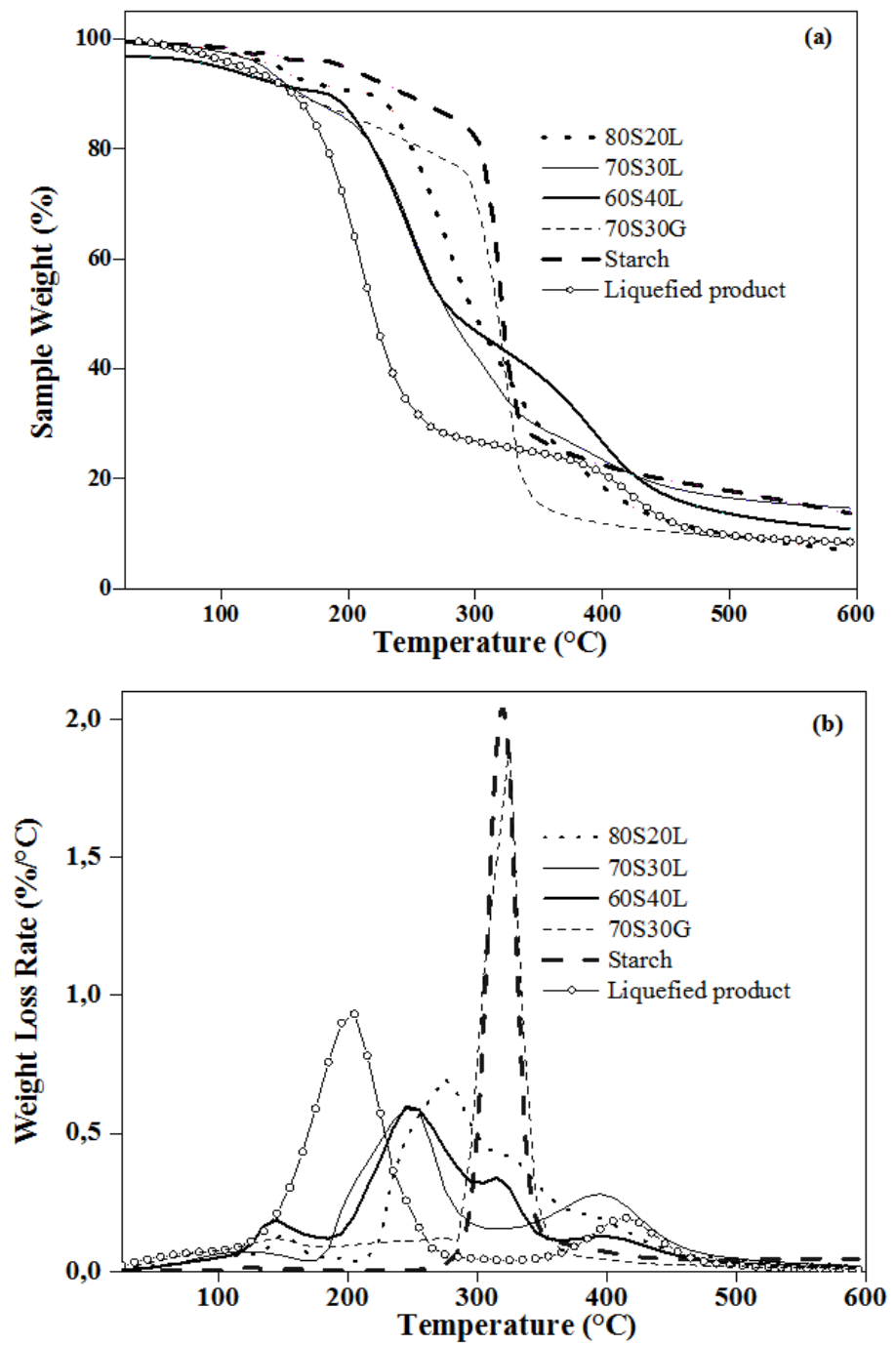

Fig 6. TG and DTG curves comparison of 40, 30 and $20 \%$ biopolyol content in blends samples. 


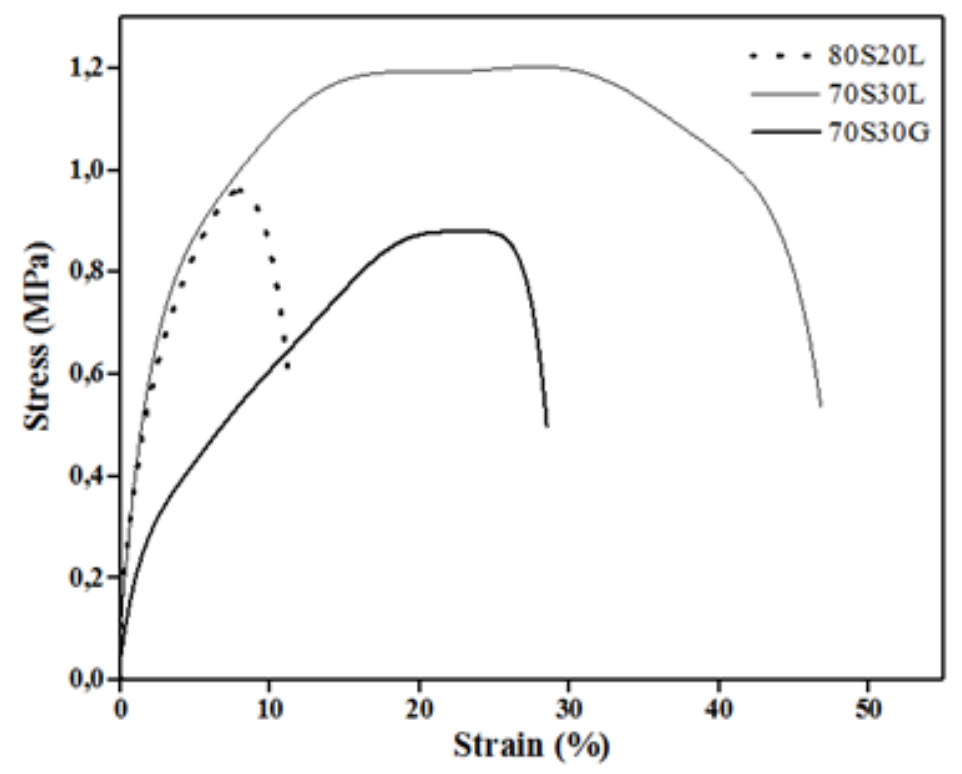

Fig. 7. Representative stress-strain curve of films with $30 \%$ of biopolyol content (70S30L) and 30\% of glycerol (70S30G). 


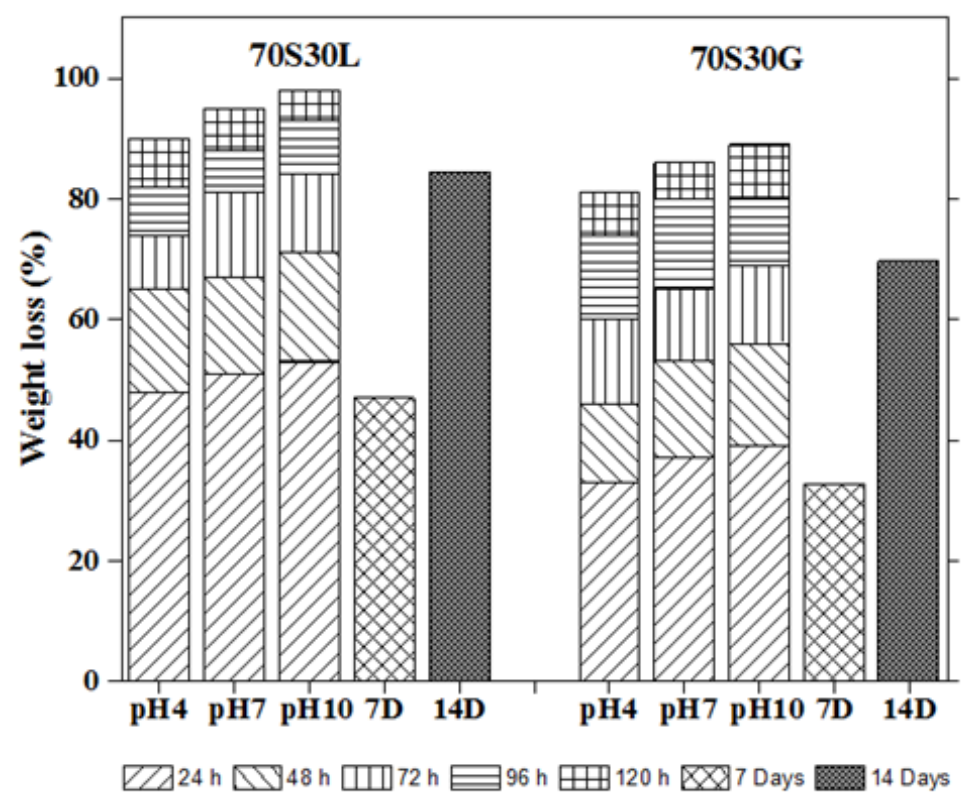

Fig 8. Degradation at hydrolytic conditions $(\mathrm{pH} 4, \mathrm{pH} 7, \mathrm{pH} 10)$ and degradation under soil (seven days, 7D and forthteen days, 14D) of sheets with $30 \%$ of biopolyol content (70S30L) and 30\% of glycerol (70S30G). 